\title{
TRABALHOS DE BERTIL MALER
}

Ao hispanista sueco Bertil Maler devemos vários trabalhos filológicos e lingüísticos referentes ao português, publicados na Suécia, em Portugal, ou mesmo no Brasil, que mereceriam melhor divulgação entre nós. Aqui desejo dar uma ligeira notícia de alguns deles, recebidos ultimamente, e, indiretamente, também de alguns outros.

1 - Orto do Esposo - Texto inédito do fim do século XIV ou começo do XV. Edição crítica com introdução, anotações e glossário. Rio de Janeiro, MEC (INL), 1956, 2 vols. (vol. I, XIV + 360 p; vol. II, 226 p.) Orto do Esposo - Correcções dos vols. I e II, estudo das fontes e do estado da língua, glossário, lista dos livros citados e índice geral. Stockholm, Alqvist \& Wiksell, 1964, vol. III, $162 \mathrm{p}$.

Minha intenção principal é dar notícia, embora só agora, do vol. III, que, não tendo saído no Brasil, ficou meio separado dos precedentes, não sendo quase conhecido entre nós. Entretanto, convém dizer algo sobre os vols. I e II.

O vol. I traz Introdução muito rápida (p. VII - IX) do Pe. Augusto Magne e um Prefácio, também rápido, do Autor (= Editor), e, nas $353 \mathrm{p}$. restantes, o texto crítico do Orto do Esposo, seguidas de $4 \mathrm{p}$. de índice e 2 de errata. Nas margens internas se indicam as folhas do manuscrito onde se localiza o texto, nas margens externas se numeram as linhas de cinco em cinco e no rodapé vem o aparato crítico. Foi adotado como base o ms. CCLXXIII / 198 da Biblioteca Nacional de Lisboa, no aparato crítico designado por A, mas a edição foi cotejada com as lições do ms. n. ${ }^{\circ}$ CCLXXIV / 212 da mesma Biblioteca, no aparato designado por B. Desprezaram-se variantes apenas ortográficas e, quando o Editor prefere a lição B, dá a de $\mathbf{A}$ no aparato. Nota-se, no Prefácio, que os dois manuscritos são muito semelhantes, mas o texto de $\mathrm{B}$, apesar de mais moderno, é melhor que o de A.

A Introdução apresenta rapidamente o Editor e discute sumariamente problemas como data, autoria, obras da mesma época, e conteúdo do Orto do Esposo. O Prefácio dá concisa mas precisamente as informações portuguesas sobre a obra anteriores a esta edição, diz algumas palavras sobre a sua história e qual é o plano dela nos seus 3 volumes.

O vol. II traz comentários visando sobretudo às fontes do texto, quase todas latinas (p. 9-189), seguidos duma "Sinopse do conteúdo do Orto do Esposo" (p. 191-217) e de um Indice de Nomes e Matérias (p. 209-223) Cada 
comentário inicia-se pela indicação da página e linha do vol. I, com precisão e clareza. Mas a disposição tipográfica compacta, se economizou espaço, tornou o texto das notas pesado e cansativo.

O que choca um pouco, e chocou muito o Editor, é o número excessivo de erros de revisão nos dois volumes, como se vê das 5 páginas de Errata que abrem o vol. III (p. 5-10) : cerca de 150 erros no vol. I e de 50 no vol. II. Choca realmente a um filólogo europeu a precária revisão de muitas edições brasileiras. Mas o fato na presente edição é agravado por ser revisão do INL e por se tratar de obra de crítica textual, em que qualquer forma errada pode ser tomada por quem a consulta como lição do texto.

Iniciando o vol. III com Correç̧ões (p. 5-10) e estas com um N.B., o Editor não esconde o seu descontentamento com as gralhas, que não se devem a descuido seu. E parece ser por isso que o vol. III, com o bem elaborado Glossário e outras informações preciosas, que faltaram no Prefácio do vol. I, foi publicado na Suécia. Quanto a nós, o fato de a edição dos vols. I e II ter saído no Brasil pôs ao alcance de maior número de interessados o precioso texto quinhentista, da época de Fernão Lopes.

O vol. III - editado na coleção Romanica Stockholmiensia, que abriga "teses e outras obras dos membros do Seminario românico", de que são editores Gustaf Holmer e Bertil Maler - contém as informações críticas que faltavam ao vol. I: "Os manuscritos" (p. 11-16), com 4 p. de facsímiles de espécimes dos ms. A e B; "Epoca da Composição" (p. 17-18); "Composição e Fontes" (p. 18-24); "Estudo Lingǘrstico do Texto" (p. 25-36); "Plano de Edição" (p. 37). Sua parte nuclear é, porém, o "Glossário" (p. 38-153, em duas colunas), ao qual se segue a "Lista das Obras Citadas" (p. 154-160) e - "Indice Geral" dos três vols. numa página. A lista das obras citadas (c. de 160 títulos, alguns múltiplos), a riqueza e precisão de informações quanto às fontes no vol. II, assim como o fato de oito anos depois de saírem os vols. I e II sair esse vol. III, mostram a constância e seriedade do Prof. Maler no seu trabalho. O caráter árduo da busca e a seriedade da pesquisa se detectam a cada mumento na consulta ao vol. II, mesmo nas declarações de que não se conseguiu encontrar a fonte deste ou daquele texto específico da obra.

Quanto ao precioso Glossário, que, declara o Autor, "pretende registrar todas as palavras do texto": pode-se dizer que contém mais do que se poderia encerrar em 115 páginas: sua documentação é precisa e concisa, indicando o n. ${ }^{\circ}$ da página e da linha do vol. I, onde ocorre o termo, às vezes dando mais de uma abonação e registrando todas as formas e accepções de interesse. A apresentação gráfica é excelente. Como ressalta o Autor, o interesse do Glossário, mais que o de ajudar a entender o texto, é sobretudo o de "reunir material para um futuro Dicionário histórico do português" Falando sobre o problema dos dicionários históricos portugueses, em notícia anterior a esta, já tive ocasião de lembrar por que a lexicografia portuguesa tão cedo não poderá ofe- 
recer-lhe solução satisfatória: falta-nos a publicação de textos medievais fundamentais, faltam-nos levantamentos auxiliares parciais, que são os glossários de cada texto, sem os quais nossas datações serão imprecisas, subjetivas e de segunda mão.

Por tudo isso, a publicação escrupulosa do texto e do cuidadoso Glossário de Orto do Esposo é um importante serviço que a Filologia Portuguesa deve ao Prof. Bertil Maler.

U'ma nota pragmática importante: o preço indicado, em 1964, é de 25 coroas suecas (a coroa sueca está a c. Cr $\$ 1,90$, no câmbio oficial) e o endereço da editora é: Almqvist \& Wiksell, Postbox 159, Estocolmo I, Suécia.

2 - "L'infinitif gérondival portugais: quelques notes sur sa propagation", separata de Stockholm Studies in Modern Philology, N.S., vol. 4, 1972, p. 250-268.

Eis aí um estudo muito rico e que trata de uma questão de especial interesse. O que o Autor chama infinitif gérondival é o infinitivo regido de $a$ com valor modal, equivalente ao gerúndio e seu concorrente vitorioso em Portugal: $a$ dizer $=$ dizendo. Qualquer infinitivo regido de $a$ que não estiver nesse caso fica excluído. A designação foi já usada por Holger Sten em 1952 e por R. Cantel em seu Précis de grammaire portugaise, em 1962. Embora entre nós ela não seja ainda corrente, parece que funciona: infinitivo gerundial.

Como se trata de estudo muito rico e que nos toca de perto e, sobretudo, saiu em publicação sueca, de pouca difusão entre nós, vou acompanhar Maler em suas considerações, resumindo-o e ajuntando na segunda parte deste apanhado algumas observações que possam representar uma contribuiçãozinha para ulterior tratamento do assunto, segundo ele indiretamente promete na p. 256.

O que interessa a B. Maler, no caso, é acompanhar sumariamente a evolução do uso do infinitivo gerundial, desde o seu aparecimento no séc. XVI até a sua vitória sobre o gerúndio em Portugal no séc. XIX, mas apenas no que diz respeito à perífrase com os "auxiliares" estar e andar Os exemplos que ele reúne nara ir são apenas quatro, dados em nota (nota 14, p. 257), para vir, ele declara não ter encontrado nenhum, e, quanto a ficar, ele prefere tratálo como verbo fundamental (nota $12, \mathrm{p} .253$ ). Seu estudo está dividido $\mathrm{cm}$ quatro secções numeradas: 1) p. 250-256; 2) 256-261;3) p. 261-267;3) p. 267-268.

Na $1 .^{\text {a }}$ secção ele apresenta o problema da história do novo sintagma, enumerando uma série de questões: a) se poderia ser precisado o ritmo do seu progresso; b) se se consumou recentemente a substituição do gerúndio pelo infinitivo gerundial; c) se essa substituição foi súbita ou lenta; d) se haveria variedades de distribuição que tivessem maior impulso; e) se se notariam hesitações ou preferências estilísticas ante algumas dessas variedades. Limita seu cs- 
tudo à história sumária da perífrase, esperando oportunidade de tratar com mais amplitude a questão. Ainda nessa secção esboça uma sistematização dos tipos de distribuição em que o infinitivo gerundial ocorre, com fundamento geral na doutrina de três estudos sobre o infinitivo. Creio conveniente especificar aqui esses estudos: 1) Th. Henrique Maurer Jr. - O Infinito Flexionado Português: estudo histórico-descritivo. CEN-Ed. USP, 1968 (esp. p. 117-124); 2) Holger Sten - "L'infinitivo impessoal et l'infinitivo pessoal en portugais moderne", in Bol. de Fil., CEFL, 1952, t. XIII, p. 83-142 e 201-256 (esp. 133139); 3) Franz Sester, Der Infinitiv im Neuportugiesischen auf Grund der Werke von Eça de Queiroz (Dissertação de Colônia), 1928 (esp. §§ 34-36). O primeiro é nosso e bem mereceria ser mais conhecido entre nós; o segundo saiu depois em publicação à parte e é dum lingüista dinamarquês, falecido em 1972, a quem devemos um estudo geral sobre "particularidades da língua portuguesa"; o terceiro eu não conheço, infelizmente.

Os dois quadros esboçados por Maler nas p. 252-256 sobre as distribuições do infinitivo gerundial e do gerúndio modal, que, como se vê da sua extensão, ocupam quase toda a seç̧ão, podem muito bem ser condensados num quadro único, pois seus constituintes são absolutamente homólogos. Aliás, bastaria só traduzir os exemplos do primeiro de "português de Portugal" para "português do Brasil"! A divisão de Maler é: I, $a, b$; II, $a, b$, para o infinitivo gerundial e $I, a, b, c ; I, a, b$, para o gerúndio. Mas a matérja é absolutamente homóloga. Condensarei os dois quadros dentro do plano do do gerúndio, usando apenas alguns algarismos romanos e arábicos na divisão e com exemplos mais concisos, a fim de que este resumo não seja mais longo que o estudo do colega sueco.

I - Infinitivo gerundial (ou gerúndio) ligado a um verbo.

1 - Em perífrase com estar, andar, ir (e vir):está a estudar, está estudando; anda a insultar-me, anda insultando-me (ou, entre nós, anda me insultando)

2 - Como adjunto adverbial com verbos diversos: acordava a pensar (ou pensando); caiu sobre a cama, a chorar (ou chorando); ficava a sonhar (ou sonhando); dormia a roncar (ou roncando)

Muitas vezes esse adj. adverbial vem introduzido por um como ou como que comparativo ou modal: ficava como a pensar, como que a pensar (ficava como pensando, como que pensando)

3 - Em concorrência com os casos residuais de accusativus cum infinitivo com os verbos de percepção ver e ouvir e com o de vontade deixar (na dupla accepção de "permitir" e de "largar" ou "abandonar") nas construções do infinitivo gerundial ou do gerúndio, mas com uma leve oposição semântica: 
Vimo-lo abrir o livro

Ouviram-no gritar

Deixei-o zombar

Deixa-o dormir
Vimo-lo a abrir o livro

Ouviram-no a gritar

Deixei-o a zombar

Deixa-o a dormir
Vimo-lo abrindo o livro

Ouviram-no gritando

Deixei-o zombando

Deixa-o dormindo

Há uma leve diferença de valor entre a construção residual de accusativus cum infinitivo e as construções do infinitivo gerundial ou de gerúndio como adj. adverbial de modo. Mas eu voltarei adiante a esse caso.

II - Infinitivo gerundial (ou gerúndio) ligado a um substantivo (ou pronome).

1 - Como complemento predicativo: Um quarentão a perverter meminas (ou pervertendo meninas!); ele a esbanjar dinheiro! (ou esbanjando dinheiro)

2 - Modificando adjunto adverbial regido de com (modo ou causa): Ficou parado, com o táxi a funcionar (ou funcionando); fazia gestos espalhafatosos, com toda gente a olhar (ou olhando).

3 - Modificando adjunto adverbial, mas com elipse da preposição com (ou, se se preferir, em oração gerundial modal, de gerúndio do verbo ter elíptico): Vi o carro passar, os vidros a chisparem (ou chisfando); ele retrucou, os olhos a fuzilarem de ódio (ou fuzilando)

Aí está, em resumo, a distribuição das estruturas em que entram as duas construçōes, ligeiramente alterada por mim. Mas continuemos rastreando a exposição do Prof. Maler.

$\mathrm{Na} 2 .^{a}$ secção, ele discute, num parêntese muito interessante, o estudo de Carim Fahlin, "Observations sur l'infinitif de narration en portugais et sur la construction du verbe commencer", publicado em Studia Neophilologica, 19, 1947, Uppsala, p. 272-292. Só possuímos números mais recentes dessa $R e-$ vista, de modo que passo rápido por essa seç̧ão. Na discussão ficam enumeradas algumas ocorrências do infinitivo gerundial em Gil Vicente, em perífrase com estar e andar, uma com ser, e um exemplo com pronome - eu cá (a) esmorecer ( $\mathrm{p}$. 261, nota 28) Não sei se o texto de Fahling registra mais este de substantivo $+a+$ inf. gerundial de valor exclamativo, do fim do Auto de Mofina Mendes: E a Mofina a bailar (= bailando)

Maler sai do parêntese da $2 .^{\text {a }}$ seç̧ão, convicto de que o terminus a quo do avanço da perífrase de andar e estar + infinitivo gerundial deve estar no início do séc. XVI, com os exemplos de Gil Vicente. Na Demanda do Santo Graal (séc XIII ou XIV), em cerca de 800 páginas só encontrou um exemplo. No séc. XVI anota ainda meia dúzia de exemplos, admitindo que não seria difícil encontrarem-se aqui e ali alguns outros "casos esporádicos" No séc. XVII, igualmente raras ocorrências. Na primeira metade do séc. XVIII, pesquisas em Antônio José da Silva deram, entre 175 exemplos da perífrase de andar e estar + inf. ger. e gerúndio, só cinco com infinitivo gerundial. 
Portanto, avanço quase nenhum. Tomou ele então a Coleção de Entremezes da Bibl. Nac. de Lisboa (66 eñtremezes, nos três tomos, cerca de 1000 páginas), que são dos últimos vinte anos do séc. XVIII. Para exatamente 200 ocorrências da perífrase, apenas $20 \mathrm{com}$ o infinitivo gerundial e as restantes 180 com o gerúndio. Não deixam, porém, de ser já $10 \%$.

Após esse resultado, entra ele na última meia página do seu estudo, que é a 4. ${ }^{a}$ secção. E a sua conclusão. O desenvolvimento do infinitivo gerundial, na língua literária, em Portugal, é do séc. XIX e deve-se sem dúvida ao fato de "o Romantismo e, sobretudo, o Realismo e o Naturalismo (...) escancararem as portas à língua popular e darem livre acesso a esse adventício ou "novo ricu" da gramática, que é o infinitivo gerundial" (p. 268).

Numa nota preciosa, de n. ${ }^{\circ} 38$, que encerra as suas notas e o seu estudo ele nos dá conta do resultado de duas pesquisas que ele fez: nos 35 primeiros capítulos da As Pupilas do Senhor Reitor, para uma ocorrência de 100 perífrases, 60 são com o infinitivo gerundial, 46 destas em diálogos; e em $O$ Primo Basílio, de um total de 133 ocorrências da perífrase, 96 são com o infinitivo gerundial, das quais $86 \mathrm{em}$ diálogos. Essa maior frequiência em diálogos parece mostrar realmente uma elevação da língua popular para a literária. E isso parece ficar corroborado pelo avanço vitorioso do infinitivo gerundial, de Júlio Diniz para Eça de Queiroz.

$\mathrm{O}$ rigor metodológico dessa pesquisa, de que saiu um artigo de 18 páginas, o rigor de documentação, a bibliografia lida, que transparece espontânea, sem afetação, a paciência de leitura e fichamento dos fatos, a modéstia do título do trabalho no seu subtítulo - "quelques notes sur sa propagation" e da redação, que não usa o termo recherche, são admiráveis. Tudo isso mostra que um filólogo também faz Lingüística. Mas o que mais interessa - e é essa uma das razões de eu tentar aqui uma resenha quase tão extensa quanto o seu texto - é uma excelente sugestão de método e de modéstia intelectual para os nossos "pesquisadores"

Não posso furtar-me à tentação de transcrever as quatro linhas finais da sua conclusão: "Quanto à época atual, não será exagero afirmar que pelo menos na perífrase o infinitivo se tornou a regra. Dizer que ambos - o gerúndio e infinitivo gerundial - se equivalem, que se pode empregar tanto o gerúndio com o infinitivo gerundial, ou vice-versa, não parece mais corresponder à situação real" (p. 268)

Agora farei algumas observações despretensiosas, que não são reparos à exposição de Maler, pois ele nem visava ao português do Brasil, nem pretendia tratar do infinitivo gerundial na sua amplitude, em descrição ou história, mas, como vimos, só da história da perífrase. O que vou discutir, para aproveitar a leitura e para lhe oferecer modestos subsídios, é um ou outro dos exemplos ilustrativos dos quadros, e o problema da oposição entre perífrase e infinitivo gerundial como adjunto adverbial, assim como a posição de ir e vir na "perifrase" Farei tudo em notas numeradas, para maior clareza. 
1 - Maler prefere excluir ficar do grupo de auxiliares do infinitivo gerundial ou do gerúndio, considerando estes como adjuntos adverbiais de $f i$ car É uma opção legítima. Mesmo com andar e estar, conforme o contexto, sobretudo quando os dois constituintes da "perífrase" ficam distanciados pela intercalação dum adjunto adverbial de lugar, modo ou tempo, sente-se a sua pequena coesão e hesitação na análise. Aliás, cabe notar que o gerúndio modal, adiunto adverbial de modo na origem, ali entrou substituindo um particípio conjunto, também de valor modal ou de circunstância acompanhante. E por isso que os transformacionalistas eliminam quase todas as perífrases nas suas análises: os critérios de testagem da coesão das perífrases, as transformaçōes ou critérios semânticos, bombardeiam a análise.

2 - Quanto a ir e vir, Maler cita em nota dois exemplos de Eça e dois de Camilo para ir e declara não ter encontrado nenhum com vir Não vou aqui analisar os exemplos citados para $i r$, mas parece-me que eles são antes de I, 2, isto é, adjuntos adverbiais, sendo as formas de ir verbos "semi-fundamentais" Não parece acontecer o mesmo com a perífrase de $i r$, e também de vir, com o gerúndio, cuja coesão resiste até o teste da transformação passiva. Tomemos os seguintes exemplos: Ele vai realizando o seu trabalho, o empreiteiro vai executando fielmente o contrato, vai chegando o fim, vou chegando ao fim do livro; ele vem realizando o seu trabalho, o empreiteiro vein executando fielmente o contrato, vem chegando o fim, venho chegando ao fim do livro. As duas primeiras frases são indiscutíveis, tanto para o auxiliar ir como para vir, ambas admitindo a transformação passiva; a terceira é também aceitável para ir e vir; a quarta parece um pouco estranha para vir, mas não de todo inaceitável. Mas a "transformação" de gerúndio para infinitivo gerundial parece que nenhuma das oito aceitará.

3 - B. Maler, notando a ausência de exemplos de infinitivo gerundial com vir e a sobriedade da documentação com $i r$, pergunta: "Como se explica essa disparidade na evolução do infinitivo gerundial na perífrase? Seria acaso pelo desejo de evitar une confusão com ir e vir seguido de $a$ de valor final?" Não sei se a pergunta sem resposta pretendeu deixar a questão aberta, ou se é já uma espécie de afirmação atenuada. Creio que se deve ir além. A construção de ir e vir com sintagma de infinitivo sem préposição, com preposição $a$ ou para (ou equivalente), representa uma inovação já do latim vulgar como substituto do supino em -um, de larga atestação nos textos cristãos e nos vulgares. E é também um fato comum a todas as línguas românicas. Até o romeno, que quase perdeu de todo o infinitivo verbal, a conserva bem. A Gramatica Limbii Romine, da Ed. Acad. R.P.R, Bucareste, 1963, 2. ${ }^{a}$ ed. dirigida por Al. Graur, Miora Avram e Laura Vasiliu como coordenadores de sub-equipes, traz no seu vol. I, $\$ 219,5$, d (p. 225-226), um exemplo com a veni "vir", regendo prep. $a$, outro com a lua, "tomar" este com a prep. pentru, "para" e outro com a se duce, "ir" "dirigir-se" com a prep. spre, "para" E em nota diz que "o infinitivo compl. circ. de fim construído com $a$ é arcaísmo" Creio, pois, que não resta dúvida de que é o infinitivo de fim que impôs a restrição. 
4 - Já vimos atrás - aliás, já o tinha notado Maler - que ir e vir não são absolutamente homólogos. Ir como auxiliar do infinitivo ou do gerúndio é não só mais freqüente como também mais vazio do sentido de movimento. Por ex., nas frases o pedieiro vai fazer a casa e pe'reiro vem fazer a casa, ambas válidas, se a primeira pode ser ambígua é, se vai implica ou não movimento, a segunda só pode indicar movimento: "o pedreiro vem para fazer a casa" Por outro lado, com vai sem idéia de movimento, a primeira frase admite a transformação passiva, ao passo que a segunda, tendo vem intacto o sentido de "movimento de deslocação para perto", não aceita transformação passiva. Há alguns casos individuais em que vir $+a+$ infinitivo tem idéia atenuada de movimento: são expressões estereotipadas do tipo de vem a calhar, vem a dar na mesma, com as quais não se argumenta. Entretanto, sempre é possível criar um contexto mais ou menos artificial, em que vir $+u+$ infinitivo pode ter um infinitivo gerundial. Por ex.: Eis por que eu venho a dizer-lhe isso a cada momento; por isso, a cada passo, venho a repetir-lhe que tome cuidado. Mas quem pode dizer isso pelo gerúndio por que há de querer usar o infinitivo gerundial?

5 - Outro caso mencionado é o de a correr, "a toda pressa" e não em combinação com ir ou vir (nota 13, p. 256) Realmente, a correr, de Portugal, como nosso correndo, esteotiparam-se como expressões adverbiais. Mas o verbo tem uso não adverbial. Eis alguns exemplos espontâneos: $O$ viajante está a correr (ou correndo) a freguesia; João vive a correr (ou correndo) mundo; em São Paulo o pedestre vive a correr (ou correndo) risco. Já escrever correndo a carta, ou escrever a carta a correr, só é possível se o sentido for "a toda pressa"

6 - Outro caso interessante é o apontado por Maurer (p. 119-120), que talvez constitua uma variante de infinitivo gerundial; é o de sem + infinitivo em emprego absoluto, "aposto" a um substantivo ou pronome, ou como adjunto adverbial de um verbo. Ex.: O Juca sem pensar no perigo; e eu sem perceber a sua malicia! $O$ menino avançou sem temer a ameaça. E fato que sem + inf. equivale ao gerúndio nesses e noutros casos. Mas parece que sem + inf. é muito mais antigo do que o infinitivo gerundial com $a+$ inf. Também não deixa de ser fato que sem + inf. e com + inf. representam as majs antigas inovaçōes infinitivas em concorrência com o gerúndio: são dos primeiros dias da língua escrita construçōes como sem calando-me (=sem calar-me), com dizendo $(=c o m$ dize'). Acontece que com dizendo também equivale a dizendo simplesmente, mas sem dizendo, a sua negação, hoje só pode ser sem dizer ou não dizendo.

7 - Nas p. 253-254, Maler inclui entre os casos de concorrentes do accusativus cum infinitivo os governados por verbos como mirar, imaginar, observar, sentir, dar com (="encontrar"), olhar (p. 255). Creio que esses não são casos de accusativus cum infinitivo. Desse tipo seriam apenas os que atrás alinhei no item I, 3, propositadamente pondo, como objeto direto dos 
verbos vimos, ouviram, deixei e deixa, as formas acusativas do pronome -o, -lo, -no. Com os outros verbos cuja presença estranhei não seria possível a forma pronominal no acusativo. Entretanto, parece-me que nem os que cu mesmo pus ros exemplos da segunda e da terceira coluna seriam propriamente sucedâneos mas concorrentes do accusativus cum infinitivo. São antes sucedâneos de outra expressão latina de verbos como aspicio, invenio, cerno, conspicio, video, audio, animadverto com objeto direto e complemento predicativo objetivo no particípio presente. Note-se que com o infinitivo gerundial ou com o gerúndio eles não são equivalentes ao acc. cum infinitivo. E note-se como os latinos acima enumerados equivalem semânticamente aos dos exemplos levantados por Maler. E a explicação é a mesma: ao particípio presente sucedeu o gerúndio modal e a este, em Portugal, alcançando por influência culta a língua do Brasil, mas sem conseguir ombrear com o gerúndio, o infinitivo gerundial.

8 - Outro caso que merece comentário ou menção é o dos complementos modais com a preposição com elíptica, em que se poderia também ver, no si-tagma formado pelo substantivo ou pronome modificado pelo infinitivo gerundial ou pelo gerúndio, o objeto direto e o complemento predicativo objetivo de gerúndio ou inf. gerundial elíptico do verbo ter. Pus como item à parte pelo fato de que esse sintagma não é popular como é aquele em que o cum não sofre elipse. Parece-me que estamos aí diante de fatos de nível socio-lingüístico diverso.

Para concluir, lembro que o uso do gerúndio nesses casos que nos ocuparam é um dos famosos "brasileirismos" que distinguem nossa sintaxe da portuguesa. Alguns dos outros famosos ou famigerados "brasileirismos", como já se tem demonstrado, representam arcaísmos da fala brasileira. Pois este também é um traço conservador da nossa fala. E o fato de a inovação portuguesa ter entre nós esse ar característico lusitano e culto seria uma contraprova, se fosse necessária, para atestar o caráter tardio da inovação portuguesa. Mas isso não é necessário: o Prof. Bertil Maler demonstrou cabalmente essa tese.

3 - A Bíblia na Consolaçam de Samuel Usque (1553), Stockholm, Alqvist \& Wiksell International, 1974, $107 \mathrm{p}$.

Bertil Maler vem se interessando por Samuel Usque desde, pelo menos, 1947, quando publicou no Bol. de Fil. do CEFL, tomo VIII, p. 261-266, "Duas notas marginais à "Consolaçam" de Samuel Usque" Em 1949, no mesmo $B F$, tomo $\mathrm{X}$, p. 344-352, voltou à Consolaçam com a nota "Las palabras ermollo y ermollecer en la Consolação de Samuel Usque" No primeiro estudo, foram as palavras alsaciones e deteiras que ocuparam a sua atenção. Seu estudo o levou a cotejar as citações bíblicas de Usque com os textos das versões judaicas do Velho Testamento feitas pelos judeus espanhóis no período medieval. 
Para isso levantou todos os passos de interesse da Biblia Medieval Romanceada (Pentateuco), editada em 1927 por Américo de Castro (Fac. de Fil. y Letras de Buenos Aires) e os da chamada Biblia de Ferrara, editada em 1553 por judeus da família de Samuel Usque, refugiados na Itália após expulsos da Espanha em 1942. Como é do seu método e hábito, ele não abandonou o veio descoberto: após explicar o étimo dessas quatro palavras e esclarecer os textos em que elas aparecem, continuou os seus estudos usqueanos. E agora publica todas as citaçōes bíblicas da Consolaçam, seguindo livro por livro do Velho Testamento, desde o Gênesis até Zacarias, que é o último a ser citado, cotejadas com o texto da Biblia de Ferrara.

Já nos artigos de $B F$ ele formulara a hipótese de que as citações de Usque se baseariam nessa Bíblia espanhola. Embora o escritor seiscentista conhecesse o hebraico e interviesse constantemente nos textos citados, às vezes evitando hebraísmos, outras vezes, parece, restituindo-os, a hipótese se confirma. Maler trabalhou com a edição que ele chama "paleográfica" quase facsimilada" (p. 7 e 8), de Mendes dos Remédios, em três fascículos, publicada em 1906-1907 em Coimbra. Essa edição, muito boa, e a única disponível, traz nas p. V-XLVII uma introdução muito interessante de Mendes dos Remédios. Seu texto é o facsímile da $1 .^{\text {a }}$ edição de Ferrara - "Empresso en Ferrara en casa de Abraham aben Usque 5313 da criaçam 27 de setembro" saída em 1553, exatamente no ano em que saiu a Biblia de Ferrara. Mas Maler adquiriu também fotocópias da edição princeps e da segunda edição.

Depois de uma sóbria Introdução (p. 5-8), vem o cotejo das citações com o texto da Biblia de Ferrara: nas páginas pares as citações de Usque, localizadas com precisão no livro da Bíblia e na edição de Mendes dos Remédios, e, nas páginas ímpares, o texto de Ferrara localizado apenas pelos capítulos e versos (p. 10-95) Vem a seguir um "Comentário" constante de notas a passos bíblicos assinalados com (*) nas citações (p. 96-99), seguidos de Abreviaturas, Conclusão, Sumário de Bibliografia e Indice (p. 100-107).

O número de citações levantadas na Consolaçam é de 718 versículos em 498 citações, porque há textos que Usque cita por inteiros. E curioso notar os livros ausentes: Levítico, Josué, Rute, Crônicas, Esdras, Neemias, Ester, Jó, Provérbios, Eclesiastes, Cânticos, Daniel, Jonas, Naum, Habacuc, Ageu e Malaquias e todos os chamados Apócrifos ou Deuterocanônicos. Naum falta, embora a obra de Usque se intitule Nahum Israel, Consolaçam às Tribulacoens de Israel composto por Samuel Usque. O nome do Profeta Naum quer dizer "consolação"

Os livros mais citados são: Isaías (219 v. em 87 cit.), Jeremias (188v. em 124 cit.) Ezequiel (146 v em 143 cit.) Deuterônomio (43 v. em 32 
cit.), Oséias ( 20 v. em 20 cit.), Miqueias (16 v. em 16 cit.), Zacarias (13 v. em 13 cit.) Salmos ( 20 v. em 13 cit.) Amós (12 v. em 12 cit.), Joel (11 v. em 11 cit.) Os outros 12 livros citados acrescentam apenas 35 versos em 30 citações.

Também esse trabalho paciente e cuidadoso é uma boa contribuição do Prof. Maler aos estudos de Filologia Portuguesa, bem como especialmente de Filologia Bíblica Hispânica. 